\title{
The Retention Problem: An Analysis of Enrolment Attrition at a Canadian College*
}

\author{
SHELDON B. UNGAR**
}

\begin{abstract}
A survey of returning and non-returning students at Scarborough College was undertaken to investigate the problem of declining retention rates at Ontario Universities. This study describes the opportunities available to and chosen by non-returning students, and then seeks to evaluate various hypotheses that have been proposed to account for enrolment attrition. Consistent with prior research, there was no evidence found to support the claim that students are being forced out of university by an inability to afford the costs of their education. Instead, the results suggested that enrolment attrition is produced by a combination of an attenuation of the student's commitment to obtain the degree and the student's awareness of and access to viable alternatives. As a result of a pervasive sense of uncertainty about the market value of a university degree, many students are willing to assay other opportunities. Specifically, those students who went to work appear to have been "pulled out" of university by the availability of a credible job. In addition, the contingencies affecting the commitment of the returning students and the students who transfer to other educational institutions are discussed. The conclusion addresses the relationship between financial circumstances and access to university, and raises questions about future enrolment patterns.
\end{abstract}

\section{RÉSUMÉ}

Une enquête sur les étudiants qui continuent à fréquenter et ceux qui laissent le Collège de Scarborough fut entreprise dans le but d'étudier le problème des taux de rétention en déclin dans les universités de l'Ontario. La présente étude s'arrête à analyser les raisons

* This paper is based on a report sponsored by and submitted to the General Policy Committee at Scarborough College. The original report was coauthored by John A. Lee, and I would like to thank him for his work on that report and for his comments on a draft of this paper. The author, of course, assumes full responsibility for this paper.

** Division of Social Science, Scarborough College, University of Toronto. 
58 Sheldon B. Ungar

d'abandon des étudiants et cherche ensuite à vérifier diverses hypothèses avancées pour expliquer la baisse des inscriptions. En conformité avec des recherches antérieures, aucune évidence n'a pu être trouvée pour supporter l'idée que les étudiants soient forcés d'interrompre leurs études universitaires à cause d'une incapacité à supporter les coûts de l'enseignement. Au contraire, les résultats de la recherche suggère que la baisse des inscriptions provient plutôt d'un manque d'intérêt pour l'obtention d'un diplôme de même que d'une meilleure connaissance de d'autres possibilités offertes sur le marché du travail. Etant donné le degré d'incertitude planant sur la valeur marchande d'un diplôme universitaire, de nombreux étudiants sont prêts à explorer d'autres avenues. Plus spécifiquement, les étudiants qui ont abandonné leurs études semblent avoir été attirés par la disponibilité d'un emploi satisfaisant. L'auteur discute également des circonstances entourant les étudiants qui retournent et ceux qui décident de transférer dans d'autres institutions d'enseignement. Les conclusions de cette étude touchent aussi au problème de l'accessibilité à l'université et des dépenses encourues; finalement, certaines questions sont posées au sujet des tendances futures des inscriptions universitaires.

During the 1970's, there has been a significant slowing in the rate of growth of university enrolment. The level of undergraduate enrolment is constituted by three factors (2):

1. The level of intake of new students,

2. the retention of students already enrolled, and

3. the number of former students who re-enter

In projecting enrolment most attention has focused on the level of intake of new students (3). Demographic forecasts indicate that the size of the university age group in Ontario (age 18-24) will begin to decline in the early 1980's. Moreover, a combination of economic factors and government policy may serve to depress the participation rate of the university age group. For example, the perception that a university degree is not a good investment may cause potential students to seek out alternatives (although there is evidence to suggest that the devaluation of the degree has been exaggerated by the media (1)).

The present study is concerned with the second factor affecting undergraduate enrolment: the decline in retention rates. The 1977/78 academic year appears to mark a watershed in undergraduate retention rates (6). All three campuses of the University of Toronto, for example, experienced a significant decline in their retention rates. Indeed, the problem was serious enough to cause the University's Office of Academic Statistics and other University bodies to undertake various studies of non-returning students. The results reported here are largely based on a study of non-returning and returning students at the Scarborough College Campus of the University of Toronto.

Table 1 shows the retention rates at Scarborough College for the past four academic years. Between 1974/75 and 1976/77, retention rates fluctuated, increasing for students enroling in some years and decreasing for those enroling in other years. However, and for the first time, the retention rates in 1977/78 dropped for students enroling in all years. This across-the-board decrease represents a loss of about 200 more students than were lost "in stream" in previous years. Moreover, preliminary analysis of enrolment at Scar- 
$\underline{\text { Table } 1}$

Retention Rates of Eligible Students at Scarborough College

(as \% of the enrolment in prevtous year)

\begin{tabular}{lcccc}
\hline $\begin{array}{l}\text { Year } \\
\text { Enroled }\end{array}$ & \multicolumn{4}{c}{ Retention Rates } \\
\hline & $1974-5$ & $1975-6$ & $1976-7$ & $1977-8$ \\
\cline { 2 - 5 } First $^{1}$ & 8.8 & 7.4 & 4.7 & 4.1 \\
Second & 76.8 & 77.8 & 87.7 & 76.9 \\
Third & 75.9 & 77.8 & 76.3 & 70.8 \\
Fourth & 48.8 & 44.4 & 46.1 & 39.3 \\
& & & & \\
\hline
\end{tabular}

1 The first year rate is very low because it represents only "repeaters" who failed to accumulate 5 credits in their first year at college.

borough College for $1978 / 79$ indicates that the drop in retention rates is not a transitory phenomenon. In fact, the retention rate from first to second year has further declined in $1978 / 79$.

Much of the attrition in enrolment has been attributed by various observers to the changing economic situation in Canada - the high rate of unemployment, too many university-qualified people chasing too few jobs requiring such qualifications, and the greater difficulty experienced by students in finding summer jobs to finance their education. However, these economic changes should not obscure the fact that there are at least three (relatively) distinct ways in which deteriorating economic circumstances can produce a decline in retention rates. First, students may be forced to leave university because they cannot afford the cost of continuing their education. The second explanation focuses on the beliefs of students. Through such things as reports about unemployed/ underemployed university graduates carried in the mass media, and the personal experience of graduates whom they know or hear about from other people, students may come to believe that a university degree has little or no economic value and, as a result, actively seek out alternatives. The final explanation is essentially an attraction hypothesis. It assumes that most students are uncertain about the value of a degree and their long-term plans, and are not strongly committed to attaining a degree. When that commitment is further attenuated by other factors (e.g.'s, poor grades, parental advice), it is hypothesized that students become receptive to the "pull" of credible alternatives. Once a student's 
commitment is attenuated, the critical contingencies are the student's awareness of and access to viable alternatives. Unlike the second approach which asserts that students leave because of their prior beliefs about the degree, the third approach suggests that students are simply uncertain about the value of the degree and are drawn out by and willing to assay alternatives.

This paper draws on several sources of data to describe the opportunities available to and choices made by non-returning students, and to evaluate the hypotheses delineated above. The primary source of data is the survey of returning and non-returning students conducted at Scarborough College. The other sources of data include individual and group interviews conducted with Scarborough students and the results of a study of non-returning students undertaken by the Office of Academic Statistics at the University of Toronto.

\section{Samples and Analysis}

All 469 full-time students who were eligible to return to Scarborough College in September 1977 but failed to do so were sent a mailed questionnaire. The rate of return of usable questionnaires was $46 \%$, an adequate return for mailed questionnaires.

To provide a basis for comparison, a random sample of 395 returning students were sent a similar mailed questionnaire. In this case, the response rate was $54 \%$. Separate analyses performed on the two samples indicated that each sample adequately represented its population in terms of sex, and academic divisions of the college.

Enrolment attrition reflects a number of distinct processes which must be taken into account in our analysis. Since undergraduates can choose to complete either a three-year or a four-year degree, the non-returning sample includes both students who are nondegreed (less than 15 credits) and students who are degreed (15 to 19.5 credits). While the acrossthe-board decrease in retention rates means that both categories of students are relevant to the problem of declining enrolment, the nondegreed and the degreed students who did not return are not equivalent and will be treated separately in most of the analysis.

Not all of the eligible students who failed to return to Scarborough College discontinued their education. Those non-returning students who are enrolled full-time in other educational institutions will be hereafter referred to as transfer students. The remaining non-returning students, most of whom are employed or seeking employment, will be referred to as working students.

The combination of the aforementioned categories produces a four-fold classification of non-returning students. When the sample of returned students is also categorized into the nondegreed and the degreed, what results is six student statuses. The number of respondents in each student status is given with the sex of the respondents in Table 2. Of the non-returning students, $36 \%$ are transfer students and $64 \%$ working students. The table also reflects an important difference between the retention rates of males and females. The data from the Registrar's Office at Scarborough College show that while retention rates do not vary by sex among the nondegreed, degreed females were $50 \%$ more likely not to return to Scarborough College than were degreed males. As will be seen, there are a number of significant sex-related differences among the non-returning students.

The next section will describe in greater detail the types of alternatives available to and selected by the non-returning students. The sections which follow will analyze those factors which may contribute to declining retention rates. 
Table 2

Number of Respondents in each Student Status by Sex

\begin{tabular}{|c|c|c|c|c|c|c|}
\hline \multirow[t]{2}{*}{ Sex } & \multicolumn{5}{|c|}{ Student Status } & \\
\hline & \multicolumn{2}{|c|}{ Returned Students } & \multicolumn{2}{|c|}{ Transfer Students } & \multicolumn{2}{|c|}{ Working Students } \\
\hline & Nondegreed & Degreed & Nondegreed & Degreed & Nondegreed & Degreed \\
\hline Male & 95 & 19 & 12 & 18 & 21 & 34 \\
\hline Female & 84 & 15 & 24 & 24 & 21 & 64 \\
\hline Total & 179 & 34 & 36 & 42 & 42 & 98 \\
\hline
\end{tabular}

\section{Alternatives and Careers}

The types of alternatives selected by non-returning students are not only interesting in their own right, but provide a means for drawing inferences about the factors underlying the decline in retention rates. The types of educational institutions selected by transfer students are shown in Table 3 . Among the males, the predominate tendency is to attend another university either to complete an undergraduate degree or to attain an advanced degree. Whereas the degreed females tend to enrol in teachers college, the non-degreed females overwhelmingly transfer to community and technical colleges.

These findings can be compared with the results of a 1972 attrition study at Scarborough College conducted by Lee (4). While the proportion of non-returning students who transferred to other educational institutions was similar in the two studies, in 1972 only two percent of transfer students enrolled in community or technical colleges. The dramatic shift to community colleges, even among the degree students, suggests that many transfer students are opting for accreditation which they believe to be more marketable than an undergraduate university degree. Since there is no evidence to suggest that female transfer students had lower grades than male transfer students, the marked differences in the type of educational institutions they select probably reflects other aspects of the opportunity structure available to females.

Turning to the working students, it was found that $83 \%$ of these former students were employed. The 1972 study found a $96 \%$ employment rate among working students. The jobs reported by the working students were classified into those that could be related to university qualifications (managerial and administrative, semi-professional) and those that were unrelated to university requirements (sales and clerical, service and labor). Whereas the application of this classification scheme to the results of the 1972 study revealed that two-thirds of the working students found jobs related to university qualifications, the proportion of such jobs declined to $37 \%$ for males and $29 \%$ for females in the current study. Significantly, the present data show no relationship between the type of jobs found by working students and their degree status (i.e., degreed or non-degreed). 
Table 3

\% of Transfer Students Selecting Other Institutions by Degree and Sex

\begin{tabular}{|c|c|c|c|c|}
\hline \multirow[t]{2}{*}{ Institution } & \multicolumn{2}{|c|}{ Nondegreed } & \multicolumn{2}{|c|}{ Degreed } \\
\hline & Male & Female & Male & Female \\
\hline $\begin{array}{l}\text { Community/ } \\
\text { Technical College }\end{array}$ & $25 \%$ & $75 \%$ & $33 \%$ & $29 \%$ \\
\hline Teachers College & - & - & 0 & 67 \\
\hline Other University & 75 & 25 & 67 & 4 \\
\hline & $100 \%$ & $100 \%$ & $100 \%$ & $100 \%$ \\
\hline & $n=12$ & $n=24$ & $n=18$ & $n=24$ \\
\hline
\end{tabular}

\section{Financial Circumstances}

In recent years Ontario students have faced increased tuition costs, greater restrictions in the student aid plan, and increased difficulty in finding employment. It is not surprising, then, that there is a widespread belief that the costs of an education may force students to leave university and find a job. The questionnaires sent to both of our samples included a variety of items that were intended to measure the financial circumstances of our respondents. The analyses conducted on these items and the findings of another study presented below all point to one conclusion: the cost of financing an education does not appear to prevent students from continuing their education. These findings, however, should not be misconstrued: those students who left university to take up jobs represent a selected group of students who presumably had the resources to enter university in the first place. Our results have no bearing whatsoever on the issue of eligible persons who are prevented from going to university (or indeed community college) by a lack of funds and restrictions in the student aid plan.

Non-returning students were asked in an open-ended item and a series of closed-ended items for their reasons for not returning to Scarborough College. For both the degreed and non-degreed working students, an inability to afford the cost of an education was ranked among the least important of the reasons for leaving university. The results obtained for the self-reported reasons for not returning are substantiated by more objective measures of financial circumstances. Among working students, nine percent reported that either their own or their parents' financial circumstances deteriorated in the past year; however, $17 \%$ of returning students reported a similar deterioration in financial circumstances.

Our results indicate that a summer job is the single most important source of funds for financing an education. Overall, the respondents in both of our samples reported that they obtained more than $40 \%$ of the income for their education from summer earning. ${ }^{1}$ While the failure to find a summer job could make it difficult for students to continue their 
education, working students were just as likely to have found a summer job as returning and transfer students. Overall, $88 \%$ of working students found summer jobs, as compared to $91 \%$ of returning students and $92 \%$ of transfer students. The only significant difference found in the rate of summer employment was incidental to the retention problem: on the whole, a higher percentage of males than females found summer jobs (95\% vs. $86 \%){ }^{2}$

A shortage of funds - such as might result from failing to find a summer job - could affect students in another way: they could be compelled to take part-time jobs during the academic year. However, analysis of the relationship between student status and working part-time failed to reveal any significant differences. Furthermore, working students who indicated that they had trouble affording their education were no more likely to hold a part-time job than students who did not report cost problems; $37 \%$ of the former and $35 \%$ of the latter students worked part-time.

Respondents were asked to report what percentage of their educational and living expenses they derived from each of the following sources of income: summer job, parttime job, savings, parents, OSAP and other loans, and scholarships. Analyses of variance performed on each of these sources of income failed to reveal any significant differences for student status. Working students received the same level of support from their parents as did returned and transfer students. $(M=22 \%)$. The amount students contributed to their own education, whether the relevant items were analyzed separately or combined to form an overall measure of self earnings, did not vary by student status. In addition, the results were not affected when controls were introduced for the sex of the respondent.

The results of a study of non-returning students undertaken by the Office of Administrative Statistics at the University of Toronto appear to corroborate our findings (5). That study investigated the relationship between the income area in which students reside and DNR rates (did not return/did not return + did return). If financial circumstances forced students to leave university, we would expect to find a negative relationship between income area and the DNR rate. However, the results of the study reveal a positive relationship between these variables at Scarborough College. Among non-degreed students with a clear standing (i.e., not on probation), the DNR rate in $1977 / 78$ was $9.7 \%$ in high income areas, $7.2 \%$ in medium income areas and 3.8\% in low income areas. Moreover, the results obtained at the other campuses of the University of Toronto are consistent with those obtained at Scarborough College. A positive relationship between the DNR rate and income area was found at the St. George Campus, while virtually no relationship was found between these variables at the Erindale Campus. While the results of such ecological analyses can be misleading, when they are seen in the light of the other findings presented here it seems clear that a lack of funds does not account for declining retention rates.

\section{Beliefs and the Pull of the Labor Market}

The second hypothesis delineated in the introduction asserts that a difference in the beliefs held by students may underlie the decision to leave university. Specifically, it is proposed that the non-returning students will be less likely than the returning students to believe that a university degree enhances their employment prospects. In order to compare the perceptions of the non-returning students with those who returned, the questionnaire included 10 items that were intended to measure beliefs about the value of a university 
Table 4

Relationship Between Student Status and Beliefs

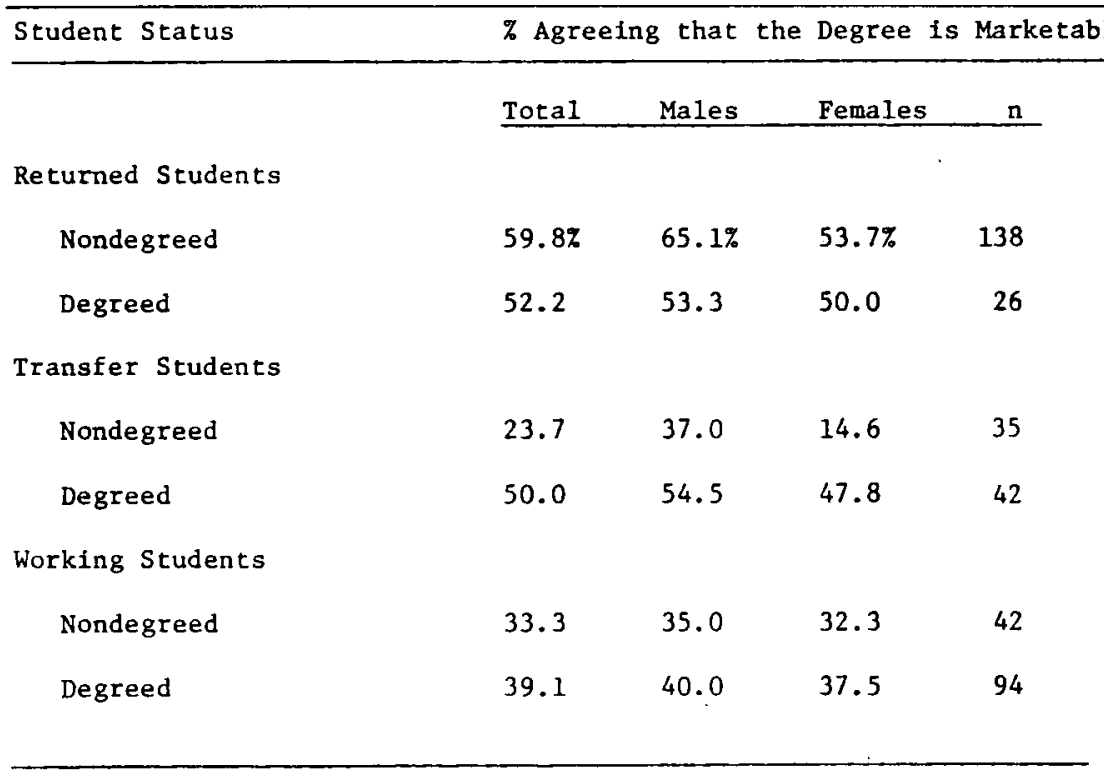

education. Several of these items were employed to measure students' attitudes about the personal and experiential value of a university education, and the results for these items did not vary significantly with student status. For example, over $90 \%$ of the respondents in each student status agreed that a university education contributed to personal growth. Clearly, the value of the university experience per se is not an issue in the retention problem.

Of the ten belief items, six pertained to the market value of a university degree. Respondents were asked to indicate whether they strongly agree, agree, disagree, or strongly disagree with the following statements: 1 . university graduates have a better chance of finding jobs (than non-graduates), 2. university graduates find better paying jobs, 3 . university graduates are better prepared for the marketplace, 4 . university graduates find more challenging and responsible jobs, 5 . so many people have a degree that it has lost its value, and 6 . the costs of financing a degree are greater than its economic benefits. Scores of 0 to 3 were assigned to the response categories, and the scores for each respondent were summed across the six items. The resulting scores were divided into two categories. Those students who scored above the median score were classified as believing that the degree was marketable, while those students whose scores were below the median were classified as not believing that the degree was marketable. This procedure was necessary to provide sufficient cases in each category for analysis.

Table 4 shows the percentage of students in each student status who agreed that a university degree was marketable. The results clearly show that, except for the degreed transfer students, the non-returning students are far less likely than the returning students 
to believe that the degree is marketable. Since most of the degreed transfer students are pursuing further education, it is not surprising that they do not devalue the degree. Indeed, $81 \%$ of this group reported that they left Scarborough College because they had completed their intentions of obtaining a three-year degree which served as a steppingstone to further education. Significantly, only $36 \%$ of the degreed working students reported that they had completed their intentions.

When the relationship between beliefs and student status is analyzed controlling for the sex of the respondents, the same pattern of results are found (see table 4). For both males and females, a significant difference is obtained between the beliefs of the returning and the non-returning students. However, it should be noted that there is an overall tendency for females to devalue the degree more than males. When the results are collapsed across student status, $51 \%$ of the males believe that the degree is marketable as compared to $42 \%$ of the females.

While our results reveal marked differences in beliefs, the fact that the survey was conducted after students made their decision to return or not to return means that the results do not provide unequivocal support for the second hypothesis. Without a longitudinal study, it is difficult to determine whether the differences in beliefs preceded the decision to not return or whether the differences are a byproduct of that decision. On the one hand, the differences in beliefs may have preceded the decision to leave, and could then be considered a "cause" of the decision. (This explanation is itself limited; there is still the need to account for the initial differences in beliefs). It is quite possible, on the other hand, that a change in beliefs followed the decision to leave university. If students are simply uncertain about the value of the degree but attracted away from university by other opportunities, they would presumably need to justify their decision. Thus, we would expect them to devalue the degree, especially if they did not favorably evaluate the alternative they had found.

According to the third hypothesis, enrolment attrition is contingent on two conditions: an attenuation of the student's commitment to a university education; and the student's information about and access to viable alternatives. The first condition, which will be discussed later, deals with those factors that create receptivity to alternatives. At this point, we are more concerned with the possibility that students are being pulled out of university by the opportunity to take up full-time jobs. For those students who are not highly committed to a university education, the offer of a good or even a tolerable job may be difficult to turn down. In that regard, it was observed earlier that only $30 \%$ of working students found jobs that could be related to university requirements. At the same time, however, $50 \%$ of the nondegreed and $60 \%$ of the degreed working students reported that a suitable job offer was an important reason for dropping out. While this disparity is hardly conclusive, it does suggest that the offer of a "passable" job can be a significant factor in the student's decision to give up his/her education.

Among working students, $36 \%$ of the degreed and $43 \%$ of the nondegreed reported that they planned a career related to their jobs. If an attractive job offer can indeed entice students away from university, then we would expect to find a strong relationship between the student's career plans and a suitable job offer as a reason for leaving. This is the case. Among students with career plans, $83 \%$ reported that finding a suitable job was an important reason for not returning; but only $44 \%$ of the students without career plans reported that a suitable job was important. 
While students may readily give up their education to take up an attractive job offer, they may also be willing to leave if they simply gain access to a passable full-time job. For example, students may be given the opportunity to convert their summer jobs into more permanent full-time jobs. Our results indicate that this opportunity is indeed important, for $52 \%$ of the nondegreed and $49 \%$ of the degreed working students reported that they had retained their summer jobs. The retention of a summer job presumably requires less effort than finding a new job. If simple access to a job was a decisive factor for those students who retained their summer jobs, then we would expect that they would evaluate their jobs more negatively than students who found other jobs. The results show a tendency in the hypothesized direction. Among students who retained their summer jobs, $54 \%$ said that a suitable job offer was important and $30 \%$ reported that they had career plans. The corresponding results for those students who had found other jobs were, respectively, $68 \%$ and $43 \%$. Thus, there is some evidence to suggest that students will avail themselves of readily accessible jobs even if the jobs are not especially attractive.

According to the attraction hypothesis, it is not students' beliefs which matter so much as their access to reasonable alternatives. If the working students are merely uncertain about the value of a degree when they make their decision to leave, then we would expect their beliefs about the degree to be contingent on their job opportunities. Specifically, students who find suitable jobs should be less likely to devalue the degree than students who do not find suitable jobs. Students who find what they believe to be suitable jobs may infer that their university experience helped them obtain such jobs. In addition, giving up one's education for a good job should create less "dissonance" than leaving for an undesirable job. Students with suitable jobs have an acceptable reason for not returning, and would not need to devalue the degree as a means of justifying their decision.

Table 5 shows the relationship between the working students' evaluation of their jobs and their beliefs about the market value of a degree. The results are clear and consistent. Working students with suitable jobs or career plans are significantly more likely to believe that the degree is marketable than working students without suitable jobs or career plans. In fact, working students with career plans are as likely as the returned students to believe that the degree is marketable (see Table 4). Moreover, while the degreed and the nondegreed are not differentiated in Table 5 , an identical pattern of results is found when the two groups are analyzed separately.

These results suggest that beliefs are indeed contingent on students' evaluation of their jobs. To further investigate the importance of these variables, they were related to the student's desire to return to university. Among the working students, there is virtually no relationship between beliefs about the value of a degree and wanting to return to university. However, career plans are significantly related to a desire to return: $32 \%$ of students without career plans would like to return, as compared to $18 \%$ of those who have career plans. Thus, both beliefs about the market value of a degree and the desire to return appear to be partly contingent on career plans. Students who have found a suitable job do not devalue the degree, but are also less likely to want to return. In contrast, students who have not found suitable jobs devalue the degree, yet are more likely to want to return to university.

The finding that career plans appear to "explain" the differences in beliefs between the non-returning and the returning students is more consistent with the third than the 
Table 5

Relationship Between Job Evaluation and Beliefs

Among Working Students

\begin{tabular}{|c|c|c|}
\hline $\begin{array}{l}\text { Degree is } \\
\text { Marketable }\end{array}$ & $\begin{array}{l}\text { Suitable Job offer } \\
\text { an Important Reason } \\
\text { for Leaving }\end{array}$ & $\begin{array}{l}\text { Plan a Career } \\
\text { Related to } \\
\text { Current Job }\end{array}$ \\
\hline & Yes & Yes \\
\hline Agree & $\begin{array}{cc}44 \% & 28 \% \\
(n=75) & (n=59)\end{array}$ & $\begin{array}{ll}54 \% & 29 \% \\
(n=39)^{1} & (n=59)\end{array}$ \\
\hline
\end{tabular}

second hypothesis. If students left university because they had come to believe that the degree was not a worthwhile investment, we would not expect their beliefs to reflect their evaluation of their job. At least for the working students, there is little evidence to suggest that they developed enduring and negative beliefs about the value of a degree prior to their decision to discontinue their education.

The evidence pertaining to the attraction hypothesis has been limited to the working students, and it is not clear whether the findings for this group can be generalized to the transfer students. Whereas full-time jobs are not readily accessible to all students, practically every student is eligible to enrol in a community or technical college. Moreover, students with access to jobs probably have to make a decision in a relatively short time, while the option of enroling in a community college is ever-available and can be postponed indefinitely, as is illustrated by the degreed students who transfer to these institutions. As a result of these differences, it is obvious that access to an alternative degree is not a sufficient condition to draw students away from university. It is also conceivable that a difference in beliefs plays a more important role in the decision to transfer than in the decision to take a job. Transfer students can bide their time in reaching a decision; students who encounter suitable job opportunities cannot.

The third hypothesis assumes that the decision to leave university is produced by a combination of attenuated commitment and an awareness of and access to credible alternatives. Unfortunately, one of the shortcomings of our survey is that no data were collected pertaining to the attenuation of commitment. However, to gain some information relevant to commitment, individual and group interviews were conducted with an admittedly haphazard sample of returned Scarborough students. ${ }^{3}$ These students were questioned about their career plans, the types of jobs they thought they were qualified for and that 
might be available to them, their awareness of alternatives to a university degree and whether they were actually investigating such alternatives. Although no attempt was made to quantify the students' responses, a relatively clear pattern of results emerged from the interviews.

The most striking feature about the responses is that most students did not express a strong commitment to attaining a degree, but appeared to have adopted a somewhat fatalistic "wait and see" attitude. The students who expressed a strong commitment were those with high marks who intended to use their degree as a stepping-stone to further education. Most students, however, did not hold long-term plans and readily expressed misgivings about the value of their education and their future opportunities. Significantly, while most of these students had thought about alternatives to a university degree, very few of them had actually investigated such alternatives. They seemed to believe that a degree obtained at a community or technical college was more marketable, but were not convinced that this was the case. The few students who reported that they were seriously considering the possibility of transferring were also dissatisfied with their performance at university.

In so far as most students are uncertain about the value of a university degree but are not actively seeking alternatives, the results appear to be consistent with the third hypothesis. However, care must be taken in drawing any inferences from these results. If these students are not highly committed to attaining a degree, the fact is they did return to university, and are therefore not equivalent to the non-returning students. Presumably, a further attenuation in their commitment is required before they become candidates for community or technical colleges. The interviews also provide some tentative leads as to those factors that could reduce commitment. Apparently, students who lack long-term educational plans and have a low grade point average are the least committed to a degree.

The previously discussed study of non-returning students at the three campuses of the University of Toronto (5) provides evidence that attests to the importance of grades as factors that can potentially attenuate commitment. In addition to income area, that study investigated the relationship between students' grade point average and the DNR rate. The non-returning students were classified into good students (GPA > 2.7) , average students (GPA $<2.7$, no probation record) and marginal students (a probation record). On the whole, the results at all three campuses revealed that marginal students had an appreciably higher attrition rate than students with a clear standing. There was also a consistent tendency for the DNR rate to increase as students' GPA decreased. In other words, a higher attrition rate was found among students with low grades. Finally, when the DNR rate is investigated while controlling for both income area and GPA, there is still a tendency for the DNR rate to be positively related to income area and negatively related to the GPA.

While we do not have data from the past, we would expect that the negative relationship obtained between the DNR rate and the GPA would also have held in prior years. At the same time, it is possible that a concern with the job market has led a proportionately greater number of students with a low GPA to transfer to take a job. But the negative relationship reported here has a further significance. In recent years, many universities have instituted more stringent guidelines for grading in order to combat the grade inflation that ostensibly occured in the 1960's. Since lower grades appear to be associated with a 
69 The Retention Rate: An Analysis of Enrolment Attrition at a Canadian College

higher DNR rate, universities may be inadvertently and somewhat ironically contributing to the shortfall of returning students at a time when budgetary considerations dictate that universities maximize their retention rates.

\section{Conclusion}

Perhaps the most significant finding of the present study is that the evidence appears to refute the hypothesis that students are being forced out of university by an inability to afford the costs of continuing their education. We do not believe, however, that this finding justifies either complacency or further moves to make students pay an even greater share of the costs of a university degree. Access to higher education is presently biased in favor of students with middle class origins; additional increases in tuition or restrictions in the student aid plan will only serve to accentuate this bias.

The fact that a positive relationship was obtained between the DNR rate and income area suggests an intriguing hypothesis. The non-returning students may be disproportionately recruited from families of higher socio-economic standing. Since the degree no longer guarantees good jobs, college-educated parents may be less inclined than parents without a degree to push their sons and daughters to attain a degree for the sake of it. Parents who never went to university may still perceive the degree as an important source of status, and even economic, mobility. In addition, students from families of higher socio-economic standing may be more able to afford time off to assay other opportunities as their families have the resources to send them through university at some later time. If there is any basis to this speculative analysis, it implies that the costs of an education are indeed salient to many of the returning students.

While the results of this study are not conclusive, the evidence appears to be most consistent with the third hypothesis. Misgivings about the value of a degree and job prospects are widely shared by students; as a result, they have become more receptive than their predecessors to viable alternatives. Job-related considerations are clearly foremost in the minds of many students and, at least for the working students, the offer of a reasonable job appears to be a critical contingency in their decision to discontinue their education. However, there is reason to suspect that the working students, especially those who are nondegreed, are not irrevocably lost to the university system. The responses of this group, including the additional "comments" added to the questionnaire, suggest that many of them wanted time off to reassess their career plans. That they may be stopouts rather than dropouts is evidenced by the fact that $55 \%$ of the nondegreed and $34 \%$ of the degreed plan to continue their education in the future - although not necessarily at a university.

The possibility of a stopout process must be understood in a broader context. Since $1973 / 74$ there has been an annual increase in the number of part-time students at Scarborough College, to the point where they now comprise over $25 \%$ of all students. These students tend to combine a part-or full-time job with their education. Work experience is not only an integral part of their education, but can provide a competitive edge in the long-run. By working, students can accumulate the job experience and cultivate the contacts that may ultimately prove to be critical in finding a good job. It is reasonable to assume that the non-returning working students were partly motivated by the desire to 
acquire competitive advantages. An implication of this strategy is that many working students will become candidates for additional education. Thus, students who do not find satisfactory employment, students who require special skills and knowledge for their work, and students who discover that their job mobility is blocked by a lack of educational qualifications may all return as part-or full-time students. If a stopout phenomenon is in fact likely to be an important trend of the future, universities will need to establish programs to attract and accomodate the reservoir of potential students.

\section{FOOTNOTES}

1. While the non-returning sample is drawn entirely from full-time students, $23 \%$ of the returning sample is composed of part-time students. In this latter group, there are many students who are either working full time or who are fully supported by a spouse's income. As a result of their special financial and education status, these part-time students cannot be considered as equivalent to the full-time students, and they have been excluded from the ensuing analysis. To maintain equivalent samples, the 5 non-returning students who met either of the preceding financial criterion were also excluded from the analysis (i.e., $2 \%$ of the non-returning sample). The number of respondents remaining in each student status is shown in Table 4.

2. Statistical analyses are not shown in the text, but are available on request from the author. All statistical analyses are based on the .05 level of significance.

3. Individual interviews were conducted with 32 students. These students were not selected on any systematic basis; they were students who were merely available to the author. Group interviews were conducted with three classes of 15,30 , and 55 students taught by the author. As part of these group in terviews, students were asked to respond to questions by a show of hands. For example, students were asked to raise their hands if they were currently investigating alternatives to a university degree; each of the students who responded was then asked for his/her reason for seeking alternatives. It should be noted that the students who were individually interviewed were not enrolled in any of the three classes taking part in the group interviews.

\section{REFERENCES}

Horace D. Beach, "Higher Education and student employment needs", The Canadian Journal of Higher Education, 8:1-22, 1977.

A.L. Darling, "Whither university enrolments? - An alternative view", The Canadian Journal of Higher Education, 8:109-116, 1977.

John R. Evans, "Problems of changing growth rates in higher education: Internal university responses", The Canadian Journal of Higher Education, 8:41-50, 1977.

John A. Lee, "Why they did not come back to Scarborough", Unpublished Paper, Scarborough College, 1973.

Office of Academic Statistics, University of Toronto, "Profile of Students who did not return: Erindale, Scarborough and St. George Campuses". 1978.

Toronto Star, "Why kids drop out of college". October 10: A10, 1978

\section{Addendum}

This addendum is based on a further study of enrolment attrition conducted in 1978 . Since the results obtained in this second study are generally consistent with those reported above, no attempt will be made to provide a comprehensive summary of the 1978 findings. Instead, the analysis presented here will focus on two critical issues raised in the original study: the role of finances and family background in attrition, and the extent to which students are committed to obtaining an undergraduate degree. 


\section{Sampling Procedures}

Questionnaires were mailed to samples of students at all three campuses of the University of Toronto as follows: at Scarborough College, all non-returning students $(\mathrm{N}=360)$ were sent a questionnaire, as were an equal number of returning students; at Erindale College, questionnaires were sent to 100 non-returning and 100 returning students; at the St. George Campus, 250 non-returning and 250 returning students received questionnaires. The response rate varied from $42 \%$ to $46 \%$.

Unlike the 1977 study which included both degreed and non-degreed students from Scarborough College, the sample for the present study includes only non-degreed students (i.e., students with less than 15 credits). While the 1978 study has the advantage of including students from all three campuses of the University of Toronto, it should be noted that the overall sample is disproportionately drawn from Scarborough College. However, preliminary analysis failed to reveal any significant differences among the three campuses. Therefore the data were collapsed across the campuses.

The total sample is composed of 640 respondents. They were divided into the following student statuses: returning students $(\mathrm{N}=356)$; transfer students - those respondents registered full-time at another educational institution $(\mathrm{N}=157)$; working students - all those not registered full-time at another educational institution $(\mathrm{N}=127)$.

\section{Finances and Family Status}

The results obtained in the original study indicated that financial circumstances were not responsible for the increase in the attrition rate. A shortcoming of that study, however, was that no data were collected concerning the social class background of students. Such data were gathered in the present study.

Consistent with last year, the present study found almost no relationship between finances and family status on the one hand, and student status on the other hand. To be concise, none of the following variables were related to student status: finding or not finding a summer job in 1978; the level of income from that summer job; working or not working part time during the $1977 / 78$ academic year; the percentage of costs the student paid for his or her education; the family income; the father's and the mother's occupational status (business or professional; white collar; blue collar); and the mother's education. However, father's education was inversely related to returning to the University of Toronto. The percentage of students who returned was $63 \%$ for fathers with less than a high school education, $50 \%$ for fathers who completed high school, and $52 \%$ with fathers with some college education.

There is one financial variable that was not considered in the original study but is related to attrition: borrowing money to pay for education. Whereas $28 \%$ of the students who borrowed money are now working students, only $16 \%$ of students who did not borrow funds are working students. This $12 \%$ difference in the rate of attrition associated with borrowing acquires a further significance when an attempt is made to explain differences in borrowing. For the sample as a whole, borrowing was significantly related to most of the other financial measures in the direction that would be expected. Thus, lower family income, failing to find a full-time summer job, paying a higher proportion of costs by themselves, and stating that finances were an important consideration in the decision to return or not return all significantly increased borrowing by students. As noted above, however, none of these 


\section{Sheldon B. Ungar}

financial variables had a direct effect on student status. As a result, it would appear that financial/family status variables have only an indirect effect on student status through borrowing. Perhaps borrowing, regardless of family status, makes students more vulnerable to work opportunities that present themselves as alternatives to full-time education.

\section{Student Commitment}

The evidence presented from the 1977 study was most consistent with the third hypothesis. Specifically, it was proposed that many students are uncertain about the value of a degree, and that when this uncertainty is coupled with other factors which serve to attenuate commitment they become receptive to the "pull" of attractive alternatives. An implication of this position is that many of the returning students are probably not strongly committed to attaining the degree and are potential candidates for dropping out. A major goal of the 1978 study was to both measure and explain differential commitment among students.

Commitment was operationalized by scaling several items that were intended to measure how open students were to employment opportunities. Strongly committed students (i.e., not-open-to- alternatives) were defined as those who never looked for a permanent job and always planned to return; would return even if offered a suitable job; or in fact did return after being offered a suitable job. In contrast, the weakly committed students were those who either sought a job or who asserted that they would definitely take one if it was suitable. On the basis of this measure, almost $30 \%$ of the returning students are classified as weakly committed to attaining the degree and might leave if a viable opportunity were available. As would be expected, almost $90 \%$ of working students are classified as weakly committed by this measure. Among the transfer students, $25 \%$ report low commitment, a result that is consistent with the fact that these students are continuing their education in other institutions.

The finding that almost one-third of returning students are not strongly committed to attaining the degree would appear to be consistent with the third hypothesis. Apparently, a substantial minority of the returning students are in a state of "flux" about their educational plans. Since commitment provides a measure of potential rather than actual drop outs, an effort will be made to explain differences in commitment. In the ensuing analysis, then, the dependent variable is commitment, which is collapsed across the three student statuses (i.e., ignoring whether the respondents are returning, transfer, or working students).

Consistent with the results obtained for attrition, none of the family status or financial variables affected commitment except for borrowing. Whereas $36 \%$ of students who did not borrow money expressed low commitment, $45 \%$ of those who borrowed money expressed low commitment. In addition, however, students' perceived financial circumstances were strongly related to commitment. Overall, $53 \%$ of students who reported that their financial circumstances were an important consideration in the decision to return or not return expressed low commitment, as compared with $34 \%$ of students who reported that financial circumstances were not an important consideration. Taken together, these results suggest that it is the students' subjective perceptions of the cost/benefits of a university education that matter more their actual financial standing.

As was suggested in the original study, the level of commitment is affected by students' grades. Whereas $34 \%$ of respondents with an A or B were open to alternatives, $47 \%$ of 
73 The Retention Rate: An Analysis of Enrolment Attrition at a Canadian College

Table 6

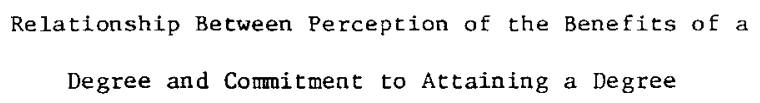

\begin{tabular}{|l|c|c|c|}
\hline \multirow{2}{*}{ Perception of Benefits } & \multicolumn{3}{|c|}{ \% Reporting Low Commitment } \\
\cline { 2 - 4 } & Item 1 & Item 2 & Item 3 \\
\hline \multirow{2}{*}{ Agree Strongly } & $41.8 \%$ & $30.4 \%$ & $26.2 \%$ \\
& $(\mathrm{n}=79)$ & $(\mathrm{n}=69)$ & $(\mathrm{n}=84)$ \\
& $33.9 \%$ & $35.2 \%$ & $36.6 \%$ \\
Disagree & $(\mathrm{n}=330)$ & $(\mathrm{n}=307)$ & $(\mathrm{n}=292)$ \\
& $44.3 \%$ & $45.9 \%$ & $45.8 \%$ \\
& $(\mathrm{n}=174)$ & $(\mathrm{n}=207)$ & $(\mathrm{n}=216)$ \\
& 62.08 & $58.0 \%$ & $62.5 \%$ \\
& $(\mathrm{n}=50)$ & $(\mathrm{n}=50)$ & $(\mathrm{n}=40)$ \\
& & & $\mathrm{N}=632$ \\
\hline
\end{tabular}

Item 1: The degree helped friends or relatives find a job.

Item 2: The degree helped friends or relatives find a better paying job.

Item 3: The degree helped friends or relatives find a more statisfying job.

*N's not equal 640 due to missing values.

respondents with a $\mathrm{C}$ average reported an openness to alternatives. In contrast, the number of credits a student has accumulated is not related to commitment. This is consistent with the finding that students with 10 or more credits towards a degree are just as likely to leave as students with less than 10 credits. As a result, low commitment students are still potential dropouts even after accumulating 10 credits.

The program area in which respondents classified themselves affects commitment. Students in the humanities were more likely to express low commitment (46\%) than students in the physical $(37 \%)$ or in the social (34\%) sciences.

Since the attitudes individuals hold are generally related to the attitudes held by significant others, several items that were intended to measure both the advice students receive and their perceptions of the experiences of friends and relatives were included in the questionnaire. The results revealed that the advice students received from significant others is the best predictor of commitment. Among students who reported that they were advised 
to stay in University, $32 \%$ expressed low commitment. In contrast, $64 \%$ of students advised to leave university reported low commitment. (Advice was also strongly related to student status: $60 \%$ of those advised to stay returned to university, as compared with $41 \%$ of those advised to leave). Significantly, neither the students' sex nor grades were related to the advice given by significant others.

Table 6 shows the relationship between commitment and students' perceptions of the value of the degree for friends and relatives. The results are clear and consistent. For each item, there is a consistent decrease in commitment as the students believe that the degree was not beneficial to friends and relatives on the job market. Moreover, and as would be expected, the advice students receive is significantly related to each of the items in Table 1. While the results of the 1977 study suggested that the perceptions a student holds are not the decisive factor in making the decision to return or not return, these perceptions may lead the student to be more or less open to alternatives which crop up.

A final factor that affected commitment was whether or not the student held a job during the $1977 / 78$ academic year. Those students who held jobs were more likely to report low commitment $(45 \%)$ than those students who did not hold jobs (34\%). Having a job may have been important in that it provided experience and access to job opportunities.

\section{Conclusion}

The results reveal that a substantial minority of returning (and transfer) students are not highly committed to continuing their education. The variation in openness to alternatives seems to be related to a number of factors. Most of these factors - e.g.'s, low grades, the need to borrow money, negative advice from significant others, the perception that the degree has not benefited graduated friends in their jobs - probably fall outside the range of phenomena the university can affect. Of course, many of the students who were categorized as having low commitment did return to university anyways. There is no way of determining with any certainty whether or not the uncommitted returning students will be the non-returning students in the next few years. However, since most of the variables that were associated with student status were also associated with commitment, it is conceivable that there are many returning students who are "dropouts waiting to happen".

However, the converse may also be true. In the 1977 study, it was reported that $55 \%$ of the non-degreed working students planned to continue their education in the future. For the 1978 study, $65 \%$ of working students indicated that they planned to continue their education in the future. 